\title{
Correction to: Occurrence and risk assessment of trace metals and metalloids in sediments and benthic invertebrates from Dianshan Lake, China
}

\author{
Yan Wu ${ }^{1,2} \cdot$ Yihui Zhou ${ }^{3} \cdot$ Yanling Qiu ${ }^{1} \cdot$ Da Chen ${ }^{4} \cdot$ Zhiliang Zhu $^{1} \cdot$ Jianfu Zhao $^{3} \cdot$ Åke Bergman $^{2,3,5}$
}

Published online: 25 July 2019

(C) The Author(s) 2019

\section{Correction to: Environ Sci Pollut Res (2017) 24:14847-14856 https://doi.org/10.1007/s11356-017-9069-3}

The article Occurrence and risk assessment of trace metals and metalloids in sediments and benthic invertebrates from Dianshan Lake, China, written by Yan Wu, Yihui Zhou, Yanling Qiu, Da Chen, Zhiliang Zhu, Jianfu Zhao and Åke Bergman, was originally published electronically on the publisher's internet portal (currently SpringerLink) on 05 May 2017 without open access.

With the author(s)' decision to opt for Open Choice the copyright of the article changed on July 2019 to $O$ The Author(s) 2019 and the article is forthwith distributed under the terms of the Creative Commons Attribution 4.0 International License (http://creativecommons.org/licenses/by/4.0/), which permits use, duplication, adaptation, distribution and reproduction in

The online version of the original article can be found at https://doi.org/ 10.1007/s11356-017-9069-3

Yanling Qiu

ylqiu@tongji.edu.cn

1 Key Laboratory of Yangtze River Water Environment (Ministry of Education), College of Environmental Science and Engineering, Tongji University, Shanghai 200092, China

2 Department of Environmental Science and Analytical Chemistry, Stockholm University, 10691 Stockholm, SE, Sweden

3 State Key Laboratory of Pollution Control and Resource Reuse, College of Environmental Science and Engineering, Tongji University, Shanghai 200092, China

4 School of Environment, Guangzhou Key Laboratory of Environmental Exposure and Health, and Guangdong Key Laboratory of Environmental Pollution and Health, Jinan University, Guangzhou 510632, China

5 Swedish Toxicology Sciences Research Center (Swetox), Forskargatan 20, 15257 Södertälje, SE, Sweden any medium or format, as long as you give appropriate credit to the original author(s) and the source, provide a link to the Creative Commons license and indicate if changes were made.

Open Access This article is distributed under the terms of the Creative Commons Attribution 4.0 International License (http://creativecommons. org/licenses/by/4.0/), which permits unrestricted use, distribution, and reproduction in any medium, provided you give appropriate credit to the original author(s) and the source, provide a link to the Creative Commons license, and indicate if changes were made.

Publisher's note Springer Nature remains neutral with regard to jurisdictional claims in published maps and institutional affiliations. 